\title{
Motivos para a prática de ginástica em academias exclusivas para mulheres
}

CDD. 20.ed. 796.4

http://dx.doi.org/10.1590/1807-55092015000100149

\author{
Deimersom Pereira FRAZÃO* \\ Carlos Alberto de Andrade COELHO FILHO* \\ ${ }^{*}$ Faculdade de Educa- \\ ção Física, Universi- \\ dade Federal de Juiz \\ de Fora.
}

\section{Resumo}

0 objetivo desta pesquisa é analisar o conteúdo do discurso de praticantes de ginástica em academias exclusivas para mulheres sobre os motivos dessa prática, com o foco direcionado para as relações que se estabelecem entre esses motivos e o binarismo sexual. Trata-se de um estudo qualitativo. Com base em um roteiro de questões semiestruturado, 23 frequentadoras de três academias de ginástica exclusivas para mulheres situadas no município de Juiz de Fora, Minas Gerais, foram entrevistadas. Concluímos que a motivação das entrevistadas para a prática da ginástica em academias destinadas exclusivamente às mulheres se mostra ancorada, fundamentalmente, na relação que as mesmas estabelecem, direta ou indiretamente, com o homem, em casa (namorados, maridos) e/ou na cena social. Quando comparadas às academias de ginástica mistas, as exclusivas para mulheres emergem como um espaço que pode proporcionar à mulher maior liberdade para: expressar as próprias insatisfações corporais; observar a outra mulher, sem que os sentimentos de competitividade aflorem como em geral afloram no ambiente em que há a presença física do homem; apresentar-se menos assujeitada a padrões corporais de vestimenta e/ou de maquiagem considerados mais belos ou elaborados, inclusive por elas mesmas. Deve-se ainda observar a possibilidade de que nas academias exclusivas as mulheres fiquem mais focadas na exercitação física; pelo fato de sentirem-se mais à vontade, consequentemente, podem se concentrar mais nas práticas e realizar os mais variados movimentos/exercícios sem constrangimentos provocados por olhares invasivos, de homens.

Palavras-chave: Mulher; Academia de ginástica; Gênero; Binarismo sexual.

\section{Introdução}

O fortalecimento do setor das academias de ginástica exclusivas para mulheres a partir da década de 90 se mostra associado ao fato de o homem ser representado como um elemento interventor negativo no contexto da prática de exercícios físicos em academias de ginástica mistas, especialmente quando provoca, com o olhar (excessivo, invasivo, crítico) direcionado para a mulher, situaçóes inibidoras e/ou constrangedoras ${ }^{1-3}$.

Contudo, a reflexão ganha novos contornos e/ ou possibilidades de aprofundamento quando compreendemos que o fenômeno de proliferação dessas instituiçôes exclusivas está vinculado à sutileza das relações que a mulher estabelece na sociedade contemporânea com o companheiro, com o olhar masculino em geral e com outras mulheres ${ }^{4}$. Ou seja, não é simplesmente o olhar do homem que se concretiza/ presentifica (não apenas) nas salas das academias de ginástica mistas, Coelho Filho e Frazão ${ }^{4}$ apontam para uma complexidade relacional que envolve a mulher e o seu homem/companheiro, a mulher e o olhar masculino, a mulher e a outra mulher.

Assim, dois elementos interligados nos parecem substanciais para justificar uma discussão associada à proliferaçấo das academias de ginástica destinadas exclusivamente às mulheres: 1 ) a pré-condição, isto é, o sexo (ser mulher) que determina a possibilidade de ingresso/matrícula nessas instituiçóes comerciais; 2 ) o fato desta pré-condição nos voltar para o problema da distinção entre sexo e gênero, na direção de que quando o status construído do gênero é teorizado como radicalmente independente do sexo, o próprio gênero se torna um artifício flutuante, com a consequência de que homem e masculino podem, com igual facilidade, significar tanto um corpo feminino 
como um masculino, e mulher e feminino, tanto um corpo masculino como um feminino 5 (p. 24-5).

Com efeito, no momento em que se procura difundir uma nova concepção de sujeito individual e sua individualidade ${ }^{6}$, que a ideia de sujeito liberto das predeterminações de uma natureza sexuada é pauta/ tema de interesse ${ }^{5}$, que se constata um aumento significativo do debate acerca da constituição de gênero ${ }^{7-8}$, a frequência comprovada nas academias de ginástica

\section{Método}

Esta pesquisa, de natureza qualitativa, baseia-se na compreensão de que as pessoas agem em função de suas crenças, percepçóes, sentimentos e valores, e que seus comportamentos têm sempre um sentido, um significado que não se dá a conhecer de modo imediato, precisando ser desvelado?.

O projeto, cujo presente artigo é um produto, foi aprovado pelo Comitê de Ética em Pesquisa com Seres Humanos da Universidade Federal de Juiz de Fora (parecer n. 204/2011).

Vinte e três frequentadoras de três academias de ginástica exclusivas para mulheres situadas no município de Juiz de Fora, Minas Gerais, foram entrevistadas. A coleta de dados foi interrompida mediante a consideração de que as informaçóes captadas atingiram um "ponto de redundância" , isto é, estavam suficientemente confirmadas e com poucas possibilidades de emergirem novas informaçóes relevantes que justificassem a continuidade da coleta.

As entrevistadas foram recrutadas entre as mulheres que participaram como voluntárias de uma pesquisa anterior por nós conduzida. Para seleção das participantes, utilizamos os seguintes critérios de inclusão: 1) praticar ginástica em academia destinada exclusivamente às mulheres que apresente uma metodologia de trabalho semelhante à encontrada nas academias mistas ${ }^{\mathrm{a}}$; 2) prontificar-se a participar, livremente, da pesquisa.

$\mathrm{O}$ roteiro de questóes semiestruturado que norteou as reflexóes durante as entrevistas, previamente validado por duas doutoras e dois doutores pesquisadoras(es) das questóes de sexo/gênero, é o seguinte: Por que você pratica ginástica? Qual o motivo, ou quais os motivos, de você frequentar uma academia de ginástica exclusiva para mulheres? Se você já frequentou academias de ginástica mistas, comparativamente, o que a trouxe para a destinada exclusivamente às mulheres? Você nota algo que considere importante exclusivas para mulheres, indicando um quadro/movimento correlato à estabilidade do sexo binário, pode oferecer elementos importantes para serem agregados a essas discussóes e/ou por elas aproveitados.

O objetivo desta pesquisa é analisar o conteúdo do discurso de praticantes de ginástica em academias exclusivas para mulheres sobre os motivos dessa prática, com o foco direcionado para as relaçôes que se estabelecem entre esses motivos e o binarismo sexual.

mencionar relacionado ao comportamento de homens e de mulheres no ambiente de academia? Há influência do seu companheiro ou da sua companheira na sua opção pela prática de ginástica em academias exclusivas para mulheres?

Como referencial teórico para analisar e interpretar o material produzido com a transcrição das entrevistas (um arquivo do "Word" composto por 26.140 palavras), utilizamos a "análise de conteúdo" ${ }^{10}$. Este referencial disponibiliza um conjunto de técnicas que permite ao pesquisador se infiltrar gradativamente nos discursos, chegando ao ponto de interpretá-los de forma a levantar questóes que a primeira vista não são reveladas. Nesse sentido, a pré-análise corresponde "a um período de intuiçóes, mas tem por objetivo tornar operacionais e sistematizar as ideias iniciais, de maneira a conduzir a um esquema preciso do desenvolvimento das operaçóes sucessivas, num plano de análise"10 (p.125).

Com a pré-análise em curso, a fim de nos familiarizarmos com os documentos e nos deixarmos contaminar, mais ainda, pelo universo investigado, foram realizadas leituras flutuantes do arquivo contendo a transcrição das entrevistas. Na sequência, foi iniciado o trabalho de categorização. A categorização temática foi usada para que pudéssemos organizar a análise através de uma condensação dos dados brutos.

Do "corpus" (material empírico coletado e transcrito) se estabeleceram, "a posteriori” (porquanto resultantes da acima mencionada pré-análise), duas categorias-chave, que optamos por apresentá-las separadamente em dois artigos. Neste artigo, portanto, diretamente associada ao seu objeto de estudo, elegemos como categoria de análise: "Motivação para a prática de ginástica em academias exclusivas para mulheres".

As entrevistadas são identificadas pela letra E, seguida dos números 1 a 23 . Ou seja, a entrevistada 1 é identificada como E1, e assim sucessivamente. 


\section{Resultados e discussão}

QUADRO 1 - Caracterização das mulheres entrevistadas.

\begin{tabular}{|c|c|c|c|c|c|c|c|}
\hline Entrevistada & Estado civil & Idade (anos) & Renda* $\left.^{*} \mathbf{R} \$\right)$ & Profissão & Trabalha & $\mathbf{X}$ & $\mathbf{Y}$ \\
\hline E1 & Solteira & 26 & $3.500,00$ & Estudante Pedagogia) & Sim & 0,5 & Sim \\
\hline E2 & Solteira & 21 & $4.500,00$ & Estudante (Jornalismo) & Sim & 5 & Sim \\
\hline E3 & Casada & 30 & $5.000,00$ & Gerente de Loja & Sim & 2 & Sim \\
\hline E4 & Casada & 46 & $6.000,00$ & "Do Lar" & Não & 9 & Não \\
\hline E5 & Solteira & 21 & $4.500,00$ & Estudante (Jornalismo) & Sim & 0,5 & Sim \\
\hline E6 & Casada & 26 & $5.000,00$ & Estudante (Mestrado em Biologia) & Não & 4 & Sim \\
\hline E7 & Solteira & 29 & $2.500,00$ & Psicóloga & Sim & 1,5 & Sim \\
\hline E8 & Solteira & 18 & $4.000,00$ & Estudante (Ensino Médio) & Não & 2 & Sim \\
\hline E9 & Solteira & 20 & $* *$ & Estudante (Ensino Médio) & Não & 2 & Não \\
\hline E10 & Casada & 35 & $5.000,00$ & Enfermeira & Sim & 4 & Sim \\
\hline E11 & Solteira & 21 & $3.500,00$ & Estudante (Jornalismo) & Não & 1 & Sim \\
\hline E12 & Solteira & 25 & $3.500,00$ & Jornalista & Sim & 2 & Sim \\
\hline E13 & Casada & 43 & $2.000,00$ & Doméstica & Sim & 10 & Não \\
\hline E14 & Solteira & 29 & $3.500,00$ & Pedagoga & Sim & ** & Sim \\
\hline E15 & Solteira & 21 & $13.500,00$ & Estudante (Direito) & Não & 4 & Não \\
\hline E16 & Solteira & 25 & $* *$ & Pedagoga & Sim & 9 & Não \\
\hline E17 & Casada & 58 & $4.000,00$ & Aposentada (Professora) & Não & 15 & Não \\
\hline E18 & Casada & 54 & $2.500,00$ & Doméstica & Sim & 6 & Não \\
\hline E19 & Solteira & 20 & $* *$ & Estudante (Medicina) & Não & 2 & Sim \\
\hline E20 & Solteira & 29 & $4.500,00$ & Professora & Sim & 3 & Sim \\
\hline E21 & Divorciada & 38 & $3.000,00$ & Professora & Sim & 4 & Sim \\
\hline E22 & Divorciada & 29 & $2.000,00$ & Representante Comercial & Sim & 2 & Sim \\
\hline E23 & Divorciada & 35 & $5.000,00$ & Professora & Sim & 4 & Sim \\
\hline
\end{tabular}

${ }^{*}$ Renda familiar ou pessoal aproximada/ informada;

**Não informou;

$\mathrm{X}=$ Tempo (em anos) de prática de ginástica em academias exclusivas para mulheres;

$Y=S e$ já frequentou academias de ginástica mistas.

As mulheres entrevistadas, ao manifestarem a condição de namoradas (das 13 solteiras, sete estão namorando; das três divorciadas, uma está namorando), de ex-namoradas, de ex-esposas e de esposas, ou mesmo no espaço mais amplo das suas reflexóes ${ }^{\mathrm{b}}$, apontam para o homem como objeto de desejo afetivo-sexual. Portanto, apesar de a nossa amostra ter sido não intencional, os depoimentos sugerem um grupo de mulheres marcado por uma heterossexualidade oposicional ${ }^{\mathrm{c}}$.

\section{Motivação para a prática de ginástica em academias exclusivas para mulheres}

Observemos o que diz a entrevistada: "Meu namorado teve influência bem forte na escolha pela academia exclusivamente feminina; tanto pela opinião dele quanto pelo fato de agradar a ele por estar em uma academia só de mulher” (E11). Quando as relações humanas são analisadas com um olhar direcionado por um discurso naturalista/biológico que determina as semelhanças e as diferenças entre os indivíduos (isto é, entre machos e fêmeas com base em características geneticamente determinadas), aspectos relacionais e políticos formadores da individualidade podem ser negligenciados ${ }^{8}$. Como interpretar, então, o posicionamento/depoimento dessa mulher, compreendendo sua singularidade numa perspectiva (pósestruturalista) ancorada ao conceito de um sujeito que participa de um todo sem ser, simplesmente, seu produto? Ou seja, uma singularidade que mantém sua força própria, mas que a mantém dentro de uma dinâmica relacional que permite construir, ao mesmo tempo, a si mesma e ao todo ${ }^{11}$.

A entrevistada afirma que o seu "namorado teve influência bem forte na escolha pela academia". Logo, é o poder do namorado/homem alimentando a escolha e sendo alimentado por ela ${ }^{\mathrm{d}}$. Mas o poder da jovem namorada/mulher também não se deixa entrever? $\mathrm{Na}$ opção de "agradar a ele 
por estar em uma academia só de mulher"? $\mathrm{Na}$ ousadia/"liberdade" associada ao próprio depoimento e à posição assumida? As práticas corporais de movimento acompanham a dinâmica social ${ }^{12}$, portanto, uma evidência se materializa: o mercado de academias de ginástica exclusivas para mulheres (em contínua expansão) foi/é nutrido por um sistema relacional de poder. Como indica Deleuze ${ }^{13}$ : "O poder 'produz realidade', antes de reprimir. E também produz verdade, antes de ideologizar, antes de abstrair ou de mascarar" (p.38). Com efeito, a relação de poder se insere em todo lugar onde existem singularidades, ainda que minúsculas ${ }^{13}$.

De fato, as mulheres de hoje se encontram distantes da submissão alienada ao representante patriarcal e/ou estrutura de poder que as estabelecia, simplesmente, como produto $^{12,14-15}$. Não nos encontramos mais no período em que as mulheres se viam determinadas (disciplinadas e controladas, se utilizamos a tipologia foucaultiana do poder) a praticar sua ginástica em academias que ofereciam uma ginástica orientada por mulheres, para mulheres, sob forte influência da dança ${ }^{4}$. Como diz Lipovetsky ${ }^{16}$, estamos diante de "um novo modelo que comanda o lugar e o destino social do feminino. Novo modelo que se caracteriza por sua autonomização em relação à influência tradicional exercida pelos homens sobre as definiçóes e significaçóes imaginário-sociais da mulher" (p.236).

Assim, no que se refere à motivação para a prática da ginástica nas academias exclusivas para mulheres, nossa interpretação deve se precaver para não criar "um mal-estar filosófico com o acirramento binarista de oposiçóes maniqueístas, com o homem mau e a mulher inocente"17 (p.72). Ao mesmo tempo, contudo, se não queremos abdicar do objetivo de conduzir à demonstração empírica, a tarefa do quadro interpretativo em vista é a compreensão de que a motivação das mulheres entrevistadas para a prática da ginástica em academias exclusivas se mostra ancorada, fundamentalmente, na relação que as mesmas estabelecem, direta ou indiretamente, com o homem, "em casa" (namorados, maridos) e/ou na cena social. Com isso posto, resta-nos caminhar no terreno das relações dialéticas, e não mais naquele que concebia o poder numa perspectiva unidirecional. Observe-se bem: poder do homem, poder da mulher.

Das 23 mulheres entrevistadas, 16 vivenciaram a experiência de frequentar academias de ginástica mistas, sendo que duas expressam sua preferência pelas instituiçóes em que os homens se fazem presentes.

Uma das que expressa preferência pelas academias mistas diz que está na exclusiva para mulheres por conta da localização da instituição na cidade e da disponibilidade de horários para a prática de atividades, dentre as quais destaca o "boxe"; e acrescenta: "eu prefiro a parte de hipertrofia. Então, eu sinto carência nessa área também. E a mista já não, a mista eu acho que já pega mais pesado" (E1). O depoimento dessa mulher sugere: de um lado, que as academias de ginástica exclusivas não estão considerando (comercialmente e/ou na atuaçáo do(a) profissional de educação física), como poderiam, dentre as opçôes de espaços e atividades, que "mais e mais mulheres estão realizando treinamento de força como parte da totalidade de seus programas de condicionamento físico" 18 (p.269); de outro, que o espaço para o trabalho com "pesos soltos" nas salas de musculação, os exercícios de força que objetivam a hipertrofia muscular, não atendem ao perfil da clientela. Senão vejamos:

Bom, a feminina é..., muito assim, restrita; os professores, assim, eu acho que eles passam a ficha muito focados no que a mulher quer em geral da academia feminina [...]; a mulher na academia feminina não quer ganhar uma definição muscular, ela só está ali mesmo por questão de saúde, de emagrecer, de perda de gordura. Então, assim, eles não trabalham muito isso. [...] $\mathrm{Na}$ academia que eu frequento, as anilhas, os pesos são reduzidos, não tem anilha superior a de 20 quilos. Eu acho que isso tudo é uma carência (E1).

Em certo sentido, nossa análise sobre o perfil da clientela vai de encontro ao que foi constatado nos estudos de Machado e Devide ${ }^{19}$ e Lessa et al. ${ }^{1}$; qual seja, que entre os principais aspectos motivacionais para a manutenção da prática regular da musculação em academias mistas, os homens tendem a enumerar a hipertrofia muscular, enquanto as mulheres apontam para a redução e/ou manutenção do peso e da gordura corporal.

Associado ao quadro delineado, considere-se que para 20 das 23 mulheres entrevistadas a opção de horários e a (diversificação/qualidade da) oferta de atividades foi/é determinante para a prática na academia exclusiva: "[...] as 'aulas' fazem a diferença [...]” (E3); "As 'aulas' também contam muito, tem de tudo o dia inteiro lá [...]” (E13). Mais do que a prática do exercício físico individual, o que as mulheres entrevistadas enaltecem são as "ginásticas coletivas", que "fazem a diferença". Trata-se de um dado que merece atenção vinculada à diminuição preocupante do nível de atividade física da população ${ }^{20}$, aos fatores que podem influenciar a aderência aos programas de exercícios físicos ${ }^{21} \mathrm{e} / \mathrm{ou}$ à prática regular de atividades físico-esportivas ${ }^{22}$; a propósito 
das academias de ginástica, quando se identificam índices de evasão próximos a $70 \%$ entre frequentadores dessas instituiçóes, a regularidade da prática nas exclusivas para mulheres, inclusive no que se refere ao montante de mulheres que frequentou academias mistas antes de optar pelas exclusivas, assume perspectiva otimista ${ }^{4}$. Mas, ainda, se o prazer emerge como uma categoria importante atrelada aos motivos da prática regular de exercícios físicos em academias de ginástica ${ }^{23}$, parece prudente estabelecer relação entre ele e a acima referida ginástica coletiva, porquanto da valoração diferenciada que lhe é atribuída pelas mulheres entrevistadas.

E sendo verdade que, em geral (ou em sua maioria), "a mulher na academia feminina não quer ganhar uma definição muscular" (E1) (associada ao trabalho de hipertrofia muscular), portanto, se certos tipos de prática e de aparência física não atendem ao perfil desta clientela, entáo, nas entrelinhas, a questão se coloca: a prática da ginástica na academia destinada exclusivamente às mulheres pode estar indicando um movimento de resistência contra um poder/discurso (por exemplo, feminista) que rechaça uma prática de si calcada numa moral que reputa ao corpo hipertrofiado da mulher um "aspecto masculinizado"? Como Hansen e VAZ ${ }^{24}$ observam acontecer em academia mista, o prestígio de mulheres fisiculturistas (mulheres que assumem uma aparência - hipermusculosa - avaliada como "masculinizada") com as pessoas do mesmo sexo não é equivalente ao dos homens da mesma categoria. Digamos que se trata de um problema complexo, como indica a reflexão de Lovisolo et al. ${ }^{25}$ :

A insistência sobre a qualidade de beleza, de feminilidade, e até sobre a vaidade feminina, exorciza o medo da masculinização da mulher que parece significar a perda de identidade do homem. A identidade se constrói relacionalmente em oposição. Se as mulheres podem ser másculas, que será dos homens? O medo da masculinizaçāo parece adquirir sua expressão máxima em relação à mulher homossexual (p.183).

A outra entrevistada que expressou preferência pelas academias mistas diz que está na exclusiva para mulheres por conta da disponibilidade de atividades e da companhia de uma amiga, mas considera o olhar do homem que se encontra presente nas mistas benéfico, além de observar que o ambiente onde só tem mulher favorece certo comportamento que lhe incomoda:

Eu acho que quando tem um ambiente onde só tem mulher, aumenta muito a aquela coisa da competitividade. Então, assim, tem muita menina muito neurótica lá, sabe! Tipo, às vezes elas não têm nada na barriga e ficam dobrando e dizendo: 'como eu estou gorda, olha o tamanho da minha barriga!' E é um desfile, sabe! A academia virou uma passarela. Então, assim, não é todo mundo, são alguns horários, algumas pessoas, e eu não gosto muito não. Isso me incomoda. [...] Uma futilidade danada [...]. E a academia mista também tem a coisa boa que é o olhar do homem, o olhar contrário, acho que isso dá um estímulo (E7).

Analisando o depoimento acima no que se refere ao incômodo manifestado, o deslocamento é inevitável. Se das 23 entrevistadas, 21 dizem se sentir mais à vontade nas academias exclusivas para mulheres, o movimento que está sendo expresso como de "competitividade", "futilidade", pode estar associado a um sentimento de "liberdade" proporcionado pelo espaço; "liberdade" de poder dizer: "como eu estou gorda, olha o tamanho da minha barriga!" Observemos o depoimento:

Então, assim, não é qualquer roupa que me deixa à vontade. Por quê?? Porque tem partes do meu corpo que eu não estou à vontade com ele, e eu não quero que as pessoas vejam isso. Por exemplo, eu vou à piscina, eu não vou colocar um micro biquine. É mais ou menos por aí. Se eu for tomar sol na minha casa, é uma coisa; se eu for chamar minhas amigas para tomar sol aqui em casa, eu posso colocar qualquer roupa, mas se já tiverem homens no lugar, talvez eu nem tire a roupa e fique de biquine (E12).

A ideia de "liberdade" ganha outro contorno, seguindo no sentido de observar, como inferimos com base no depoimento que aparece na sequência. $\mathrm{Ou}$ seja, nas academias exclusivas a mulher pode se sentir mais livre para observar a outra mulher, e a "competitividade" acima percebida (o "desfile", a "passarela") pode passar a ser lida como "comparação":

Eu quis malhar na academia feminina agora porque me sinto mais à vontade. Porque na mista é muita questáo de mostrar e tal, de ter que estar bonita para ir malhar; e eu nunca fui muito disso. Entáo, eu acho que na academia feminina rola muito isso; de eu sair do meu serviço, pegar uma bermuda, um tênis, e vou, entendeu? Não tem muito essa comparação, mas ao mesmo tempo tem essa coisa de observaçáo da outra, que rola muito mesmo. Rola muito isso de observação da outra na academia feminina. Náo sei se rola de comparação, porque eu não tenho muita, assim, intimidade com as pessoas lá dentro, mas de observação, sim. Você vê que as pessoas quando 
chegam te observam, e o modo que você malha, te observam. As minhas amigas que malham em academias mistas falam que não, que não rola isso não nas academias mistas; rola mais é essa coisa de azaração e tal, ir malhar com o intuito de ver o cara que está a fim (E16).

As entrevistadas sublinham que nas academias mistas, pelo fato de o contexto relacional implicar na presença física de "uma terceira pessoa" (o homeme), é mais complicado. Observemos os trechos: "Depois que eu entrei, eu vi a diferença que tem com as outras. É muito bom um lugar que só tem mulher" (E20);

[...] eu me sinto muito melhor na feminina mesmo. Até meu treino, pois acho que quando você fica à vontade, você se dedica mais. Por exemplo, quando eu malhava na academia mista, eu me preocupava mais com estereótipo do que tudo. Tipo assim: 'ah, vou de cabelo arrumado, vou passar rímel.' E na de mulher não (E11); É muito bom não precisar ir toda combinando, toda bonita, sem me preocupar em suar e atrapalhar cabelo ou maquiagem. Lá a gente fica à vontade, sem ter homem para ficar reparando se você está bem, ou mal. Se é para homem ver, que veja você bonita e não toda avacalhada, cansada, desarrumada e suada (E23).

Portanto, diferentemente do que expressam as entrevistadas 1 e 7 (respectivamente: “[...] eu me sinto mais à vontade na mista. Sei lá, eu acho que o pessoal da mista, por envolver homens e mulheres, eu acho que eles são mais comunicativos” ; “[...] a academia mista também tem a coisa boa que é o olhar do homem, o olhar contrário, acho que isso dá um estímulo"), para 14 das 16 mulheres que vivenciaram a experiência de frequentar academias de ginástica mistas, a opção pela exclusiva foi também respaldada no desejo de evitar certo olhar que lhes era frequentemente direcionado por homens, nas mistas; situaçóes, por exemplo, em que homens prendem fixamente o olhar em meninas que se exercitam em aparelhos como aqueles que permitem um movimento de afastar e unir as pernas ${ }^{24}$.

No mesmo diapasão seguem as sete mulheres entrevistadas que não vivenciaram a experiência de frequentar academias de ginástica mistas. Elas "imaginam" a interferência dos homens nas academias mistas: "Ah, porque, assim, a gente fica mais à vontade, tem mais liberdade. Assim, liberdade para fazer exercícios, aquele abaixa e levanta. É por aî" (E4); "Acho que vergonha, entendeu? Por isso que eu prefiro a feminina. [...] Ah, ao homem, né! [...] Aí você não pode fazer determinados... Aquele negócio..., de abrir perna, entendeu? É isso" (E9); "Na academia é assim, tem os movimentos da ginástica, da musculação, que a gente tem que ficar deitada, agachada, e isso deixa a gente meio sem graça. [...] Eu acho que se tivesse homem lá eu ficaria diferente" (E18).

Para 21 das 23 entrevistadas, a academia de ginástica exclusiva para mulheres representa um espaço que lhes proporciona maior liberdade para a prática de exercícios físicos. Portanto, parafraseando $\mathrm{NEGRI}^{11}$, nos parece legítimo interpretar que, para essas mulheres, a liberdade quer fazer-se corpo.

E agora, recuperando nosso objetivo de conduzir à demonstração empírica caminhando no terreno das relações dialéticas, nos resta argumentar a favor do poder que a mulher tem hoje de optar por praticar seu exercício físico distante de certo olhar (excessivo, invasivo, crítico) inibidor e/ou constrangedor, do homem ${ }^{\mathrm{g}, 1-3}$.

Lembremos: "Até meu treino, pois acho que quando você fica à vontade, você se dedica mais" (E11). Ou ainda: “[...] ficava sem jeito de fazer determinado tipo de exercício, ficava mal mesmo, pulava alguns que me mostravam mais e que os homens aproveitavam para olhar. Eles eram muito indiscretos" (E21). Decerto, os depoimentos nos fazem considerar a possibilidade de que nas academias exclusivas as mulheres fiquem "mais focadas no treino mesmo" (E2).

Tanto mais, se o cuidar-se de si é "um princípio válido para todos, todo o tempo e durante toda a vida" 26 (p.53), se "não há idade para se ocupar consigo" 26 (p.54), se existem "os cuidados com o corpo, os regimes de saúde, os exercícios sem excesso, a satisfação, tão medida quanto possível, das necessidades"26 (p.56), se é necessário "estar bem" e portanto "correr atrás" (E21) para atrair um possível pretendente, então nada melhor do que ocupar-se de si em um ambiente agradável, que propicie um maior nível de concentração, com práticas o mais prazerosas possíveis.

As entrevistadas evidenciam o desejo de seduzir, o namorado, o marido, o possível "affair". Contudo, para essas mulheres, em certos momentos, assumindo determinados movimentos ginásticos, é bom "não ter homem para ficar babando" (E23). Conforme LipoveTsKY $^{16}$, não mais vivemos o tempo em que a mulher "não era nada além do que o homem queria que fosse" (p.236). Dito isso, importa notar que no extremo contrário à idealizaçáo passiva da mulher, como almejava o positivismo, da mulher objeto consumível, instrumento do prazer de outrem, podemos verificar uma relaçáo de poder entre a mulher e o homem ${ }^{27}$ : "Se é para homem ver, que veja 
você bonita [...]” (E23). Ai sim, como queira ficar/ provocar a mulher, frente ao homem "babando".

Tendo em vista a análise e a interpretação dos dados empíricos coletados no presente estudo, destacamos as seguintes conclusóes.

A opção de horários e a diversificação da oferta de atividades foram/são determinantes para a prática na academia de ginástica exclusiva para mulheres. Mais do que a exercitação física individual realizada em "salas de musculação", por exemplo, associada ao trabalho de força/hipertrofia muscular (trabalho que parece não encontrar valoração destacada no interior das academias de ginástica exclusivas para mulheres, tanto pela clientela frequentadora quanto consequentemente na consideração dialética dos aspectos comerciais associados à oferta de serviços), o que as mulheres entrevistadas enaltecem são as "ginásticas coletivas", que "fazem a diferença".

O estudo nos mostra, contudo, que a motivação das entrevistadas para a prática da ginástica em academias destinadas exclusivamente às mulheres se mostra ancorada, fundamentalmente, na relação que as mesmas estabelecem, direta ou indiretamente, com o homem, "em casa" (namorados, maridos) e/ ou na cena social. É uma constatação que nos remete a Bourdieu ${ }^{28}$ quando diz:

A divisão entre os sexos parece estar "na ordem das coisas", como se diz por vezes para falar do que é normal, natural, a ponto de ser inevitável: ela está presente, ao mesmo tempo, em estado objetivado nas coisas (na casa, por exemplo, cujas partes são todas "sexuadas"), em todo o mundo social e, em estado incorporado, nos corpos e nos habitus dos agentes, funcionando como sistemas de esquemas de percepção, de pensamento e de ação (p.16).

Com efeito, quando comparadas por nossas entrevistadas às academias de ginástica mistas, as exclusivas para mulheres emergem como um espaço que pode proporcionar à mulher maior liberdade para expressar as próprias insatisfaçóes corporais. Representam ainda um espaço no qual a mulher pode se sentir mais livre para observar a outra mulher, sem que os sentimentos de competitividade e/ ou comparatividade aflorem como em geral afloram no ambiente em que há a presença física do homem.

Relacionado aos depoimentos coletados e às conclusóes que se impóem nos dois parágrafos acima, deve-se também registrar a possibilidade de que na academia exclusiva a mulher se sinta menos assujeitada a apresentar-se enquadrada em padróes corporais de vestimenta e/ou maquiagem considerados mais belos ou elaborados, inclusive por elas mesmas. Ou seja, diferentemente do que aqui denominamos de movimento de (pré) produção mais complexa da aparência, conforme pode se estabelecer associado ao vislumbre da prática da ginástica na academia mista, parece que na exclusiva a mulher tem possibilidade de lidar com essa necessidade (por exemplo, de pensar/selecionar na/a roupa que vai utilizar na ginástica/academia, após sair do trabalho) de forma mais tranquila.

Se a história indica que, para atender a uma demanda de boa forma vinculada à lógica patriarcal, as mulheres se viam determinadas (disciplinadas e controladas) a praticar sua ginástica em grupos exclusivamente femininos ${ }^{4}$, esta pesquisa fornece elementos que nos permitem argumentar a favor do poder que a mulher tem hoje de optar por praticar seu exercício físico distante de certo olhar (excessivo, invasivo, crítico) inibidor e/ou constrangedor, do homem. Nesse sentido, deve-se observar a possibilidade de que nas academias exclusivas as mulheres fiquem mais focadas na exercitação física; pelo fato de sentirem-se mais à vontade, consequentemente, podem se concentrar mais nas práticas e realizar os mais variados movimentos/exercícios sem constrangimentos provocados por olhares invasivos, de homens.

Por fim, importa salientar que o problema abordado pelo presente estudo, associado à discussão estabelecida acerca das mudanças na ocupação de espaços sociais por mulheres, com atenção para o "lócus" das academias de ginástica, é relativamente novo no campo da Educação Física não formal e, portanto, carente de investigaçôes.

\section{Notas}

a. Isso porque, em Juiz de Fora, encontra-se situada uma unidade da franquia Curves (academia de ginástica exclusiva para mulheres), oferecendo uma metodologia de treinamento que se diferencia da encontrada nas academias mistas; trata-se de um circuito padronizado de exercícios que é realizado em 30 minutos. Assim, se concordarmos que a especificidade desse programa rápido de exercícios pode ser determinante no que diz respeito à opçáo pela escolha da instituição, as 
questôes de sexo/gênero por nós objetivadas poderiam emergir com menor representatividade do que num contexto onde não houvesse tal diferencial.

b. "Ah, aquela coisa de que uma mulher se arruma para outra, eu não acredito. Não é possível! Eu, quando me arrumo para sair, para ficar bonita, eu não quero que outra mulher olhe para mim, eu quero que o cara olhe para mim” (E5).

c. Disso se colhe, para futuras investigaçôes, algumas questóes: Qual a orientaçáo sexual declarada (heterossexual, bissexual, homossexual) de frequentadoras de academias de ginástica exclusivas para mulheres? Mulheres homossexuais apresentam motivos diversos dos que são apresentados pelas heterossexuais para a prática da ginástica em academias exclusivas para mulheres? Em quais aspectos? Lésbicas frequentadoras de academias de ginástica exclusivas para mulheres podem contribuir com a pesquisa/discussão que se estabelece associada aos "problemas de gênero"? Como masculinidades e feminilidades podem se manifestar na sexualidade lésbica presente em academias de ginástica exclusivas para mulheres?

d. Algumas das entrevistadas se mostram solidárias à vontade dos companheiros. É um movimento que também nos remete para o assédio de homens nos contextos em que há exercitação física, como pode acontecer em academias de ginástica mistas; consequentemente, a prática na academia exclusiva vai contribuir, por exemplo, para a mitigação de atritos com companheiros ciumentos. Trata-se, importa notar, de um movimento que se estabelece associado a complexas relaçóes de tensão presentes na trajetória das mulheres nos espaços sociais de "emancipação" e de "subordinação", que são analisadas e desveladas com o devido cuidado no outro artigo que se desdobra desta pesquisa, aludido na seção Método.

e. Vale observar, neste ponto, que as academias exclusivas para mulheres frequentadas pelas nossas entrevistadas utilizam em seus quadros de trabalho profissionais de educação física do sexo masculino; portanto, há o olhar masculino profissional, diferentemente, por exemplo, da franquia Curves, que só trabalha com profissionais mulheres. Contudo, parece que para nossas entrevistadas a presença desses profissionais do sexo masculino não representa problemas: "[...] é no centro, é barato, tem muita aula, não tem homem. Quer dizer, até que tem homem, mas é só professor; aí não vale, eles ficam lá, mas ninguém liga. Se fosse outro homem, com certeza, a mulherada iria reclamar" (E22).

f. Ou podem mesmo transpor, imaginariamente, para as academias mistas, a experiência cotidiana de interação com homens em outros ambientes. Ou recebem informaçóes de "amigas" que já frequentaram academias mistas etc.

g. Ainda assim, compreendendo que as "relaçóes de poder são relaçóes diferenciadas que determinam singularidades (afetos)"13 (p.38), não podemos deixar de assinalar a questáo que se abre para outros trabalhos, associada ao possível assédio e/ou olhar invasivo de uma lésbica na academia exclusiva para mulheres.

\begin{abstract}
Reasons to work out at female-only fitness clubs

This research aims to analize the speech contents of women who work out at female-only fitness clubs, on the grounds of such a practice, with the focus directed to the relationships established between the reasons for this practice and sexual binarism. This is a qualitative study. Based on a semistructured survey, twenty three women attending three female-only fitness clubs located in the city of Juiz de Fora, Minas Gerais, were interviewed. We have concluded that respondents' motivation to work out at female-only fitness clubs was demonstrated to be primarily anchored in the relationship they have, directly or indirectly, with the man at home (boyfriends, husbands) and / or in the social scenery. When compared to mixed gyms, those exclusively for women emerge as a space which can provide women greater freedom to: express their own body dissatisfaction and watch another woman without giving rise to feelings of competitiveness, as usually happens in environments with men around. They also present themselves less subjected to body patterns regarding dress and / or makeup, which are considered to be more beautiful or elaborate, even if by they themselves. Also noteworthy is the possibility that in female-only fitness clubs, women are more focused on the physical drilling, since they feel more at ease, thereby focusing more on the exercises and performing movements / exercises without the constraints caused by men's invasive glances.
\end{abstract}

KEY WoRDS: Woman; Fitness club; Gender; Sexual binarism. 


\section{Referências}

1. Lessa P, Furlan CC, Capelari JB. Pedagogias do corpo e construção do gênero na prática de musculação em academias. Motrivivência. 2011;37:41-50.

2. Neiva G, Gomes EMP, Costa JS. Academias de ginástica só para mulheres: inovação ou tradição? $15^{\circ}$ Congresso Brasileiro de Ciências do Esporte; 20 Congresso Internacional de Ciências do Esporte; 16-21 set 2007; Pernambuco, BR. Pernambuco: CONBRACE/CONICE; 2007. [citado 13 nov 2013]. Disponível em: http://www.cbce.org.br/cd/ resumos/215.pdf.

3. Mascarenhas F, Vieira CA, Marques TMA, Borges PJA, Silva BO, Santos WB. Acumulaçáo flexível, técnicas de inovação e grande indústria do fitness: o caso curves Brasil. Pensar Prát. 2007;10:237-59.

4. Coelho Filho CAA, Frazão DP. Prática de ginástica em academias exclusivamente femininas. Motriz. 2010;16:269-80.

5. Butler J. Problemas de gênero: feminismo e subversão da identidade. Rio de Janeiro: Civilização Brasileira; 2010.

6. Hall S. A identidade cultural na pós-modernidade. Rio de Janeiro: DP\&A; 2006.

7. Narvaz MG, Koller SH. Metodologias feministas e estudos de gênero: articulando pesquisa, clínica e política. Psicol Est. 2006;11:647-54.

8. Narvaz MG, Koller SH. A marginalização dos estudos feministas e de gênero na psicologia acadêmica contemporânea. Psico. 2007;38:216-23.

9. Alves AJ. O planejamento de pesquisas qualitativas em educação. Cad Pesq. 1991;77:53-61.

10. Bardin L. Análise de conteúdo. São Paulo: Edições 70; 2011.

11. Negri A. 5 Liçóes sobre o império. Rio de Janeiro: DP\&A; 2003.

12. Mathias MB, Rubio K. As práticas corporais femininas em clubes paulistas do início do século XX. Rev Bras Educ Fís Esporte. 2010;24:275-84.

13. Deleuze G. Foucault. São Paulo: Brasiliense; 2005.

14. Badinter E. Rumo equivocado: o feminismo e alguns destinos. Rio de Janeiro: Civilização Brasileira; 2005.

15. Borges CC. Mudanças nas trajetórias de vida e identidades de mulheres na contemporaneidade. Psicol Est. 2013;18:71-81.

16. Lipovetsky G. A terceira mulher: permanência e revolução do feminino. Sáo Paulo: Companhia das Letras; 2000.

17. Votre SJ, Lovisolo HR. Novos rumos do feminismo. In: Votre SJ, organizador. Gênero e atividade física. Rio de Janeiro: Mauad; 2011. p.71-6.

18. Fleck J S, Kraemer JW. Fundamentos do treinamento de força muscular. Porto Alegre: Artmed; 2006.

19. Machado LP, Devide FP. Representaçóes de homens e mulheres sobre a prática da musculação em academia. Lect Educ Fís Deportes. 2007;12:1-4.

20. Organización Panamericana de la Salud. Impulso panamericano en favor de una dieta saludable y actividad física. Washington: PAHO Foundation; 2006. [citado 4 mai 2014]. Disponível em: http://www.paho.org/Spanish/DD/ PIN/ps060228.htm\#Top.

21. Rodrigues NS, Coelho Filho CAA. Influência da audição musical na prática de exercícios físicos por pessoas adultas. Rev Bras Educ Fís Esporte. 2012;26:87-95.

22. Coelho Filho CAA, Andrade RGN. Motivos de um indivíduo para praticar atividades físico-esportivas. Psicol Est. 2013;18:475-85.

23. Balbinotti MAA, Capozzoli CJ. Motivação à prática regular de atividade física: um estudo exploratório com praticantes em academias de ginástica. Rev Bras Educ Fís Esporte. 2008;22:63-80.

24. Hansen R, Vaz AF. "Sarados" e "gostosas" entre alguns outros: aspectos da educação de corpos masculinos e femininos em academias de ginástica e musculação. Movimento. 2006;12:133-52.

25. Lovisolo HR, Soares AJ, Bartholo TL. Feministas, mulheres e esporte: questôes metodológicas. Movimento. 2006;12:165-91.

26. Foucault M. História da sexualidade 3: o cuidado de si. Rio de Janeiro: Graal; 1985.

27. Sant'Anna AR. O canibalismo amoroso. Rio de Janeiro: Rocco; 1993.

28. Bourdieu P. A dominação masculina. Rio de Janeiro: Bertrand Brasil; 2002.

\section{Agradecimento}

Os autores agradecem o apoio financeiro da CAPES. 
Frazão DP \& Coelho Filho CAA.

ENDEREÇO

Carlos Alberto de Andrade Coelho Filho

Faculdade de Educação Física

Universidade Federal de Juiz de Fora

Campus Universitário

Recebido para publicação: 22/11/2013

Revisado: 05/05/2014

Aceito: 25/10/2014

36036-90o - Juiz de Fora - MG - BRASIL

e-mail: carlos.coelho@ufjf.edu.br

158 • Rev Bras Educ Fís Esporte, (São Paulo) 2015 Jan-Mar; 29(1):149-58 